\title{
Association between the HMGB1/TLR4 signaling pathway and the clinicopathological features of ovarian cancer
}

\author{
CAIXIA JIANG ${ }^{1 *}$, XIAOYAN QU ${ }^{1 *}$, HUIHUI KE ${ }^{2}$, WEI GONG $^{2}$, RONG CHEN $^{3}$, \\ WEIHONG YANG ${ }^{3}$ and ZHONGPING CHENG $^{3}$
}

\begin{abstract}
${ }^{1}$ Department of Gynecology and Obstetrics, Yangpu Hospital, Tongji University School of Medicine, Shanghai 200090; ${ }^{2}$ Department of Gynecology and Obstetrics, Shanghai Pudong Hospital, Fudan University School of Medicine, Shanghai 510070; ${ }^{3}$ Department of Gynecology and Obstetrics, Shanghai Tenth People's Hospital, Tongji University School of Medicine, Shanghai 200072, P.R. China
\end{abstract}

Received January 16, 2018; Accepted June 18, 2018

DOI: $10.3892 / \mathrm{mmr} .2018 .9271$

\begin{abstract}
In the present study, the expression levels of high-mobility group protein B1 (HMGB1), Toll-like receptor 4 (TLR4), nuclear factor (NF)- $\kappa \mathrm{B}$ and tumor necrosis factor (TNF)- $\alpha$ in malignant epithelial ovarian cancer (MEOC) were investigated in regards to several clinicopathological characteristics. A total of 20 patients with MEOC who underwent surgery were recruited in the present study. The mRNA and protein expression of HMGB1, TLR4, NF- $\kappa \mathrm{B}$ and TNF- $\alpha$ was determined in patients with MEOC and compared with expression levels in 20 patients diagnosed with benign ovarian cysts (BOC). It was demonstrated that the mRNA and protein expression of HMGB1, TLR4, NF- $\kappa \mathrm{B}$ and TNF- $\alpha$ in MEOC was significantly increased, compared with the BOC group $(\mathrm{P}<0.01)$. The gene and protein expression of HMGB1, TLR4, NF- $\kappa \mathrm{B}$ and TNF- $\alpha$ was significantly increased in the advanced tumor stage and poorly differentiated group $(\mathrm{P}<0.01)$. The present study suggested that the HMGB1/TLR4 signaling pathway was overactive in MEOC, and was associated with MEOC tumor cell proliferation, invasion and metastasis. Furthermore, this may have been mediated via NF- $\kappa \mathrm{B}$ signaling.
\end{abstract}

\section{Introduction}

Ovarian cancer (OC) is the most lethal malignant tumor type in gynecology and a common cause of cancer-associated mortality in females worldwide. According to the statistics, more than two-thirds of OC cases are diagnosed at an advanced stage,

Correspondence to: Professor Zhongping Cheng, Department of Gynecology and Obstetrics, Shanghai Tenth People's Hospital, Tongji University School of Medicine, 301 Middle Yan Chang Road, Shanghai 200072, P.R. China

E-mail: mdcheng18@tongji.edu.cn

${ }^{*}$ Contributed equally

Key words: ovarian cancer, high-mobility group protein B1, toll-like receptor 4 , nuclear factor- $\mathrm{\kappa B}$, clinicopathological features with a five-year survival rate of $\sim 30 \%(1,2)$. Despite substantial advances in $\mathrm{OC}$ research, the mortality-to-incidence ratio and overall survival rate remains low (3). To gain further insights into the pathogenic mechanisms and to improve the treatment of OC, it is necessary to further explore the molecular biology that characterizes OC cells.

High-mobility group protein B1 (HMGB1) is a highly conserved, non-histone chromatin-binding extracellular nuclear protein. HMGB1 binds chromatin, stabilizes nucleosomes, regulates nuclear transcription and acts as an extracellular signaling molecule $(4,5)$. It is thought that HMGB1 is actively secreted by tumor cells, and passively released from necrotic cells to the tumor microenvironment (6). Recent studies have demonstrated that HMGB1 is closely associated with tumorigenesis, angiogenesis and metastasis in a number of malignancies $(3,7,8)$. Increased expression of HMGB1 has been reported in various tumor types, including ovarian, breast, prostate, colorectal and gastric cancer, and is associated with poor survival (9). In addition, high HMGB1 expression is associated with poor differentiation, a high stage and a positive lymph node status in OC (10). Toll-like receptors (TLRs) are essential components of innate immunity that enhance the function of HMGB1 in cancer, by creating a procancerous environment through inflammation, angiogenesis and cell death (11). As an important damage-associated molecular pattern (DAMP), HMGB1 activation of TLRs expressed on tumor cells initiates pro-inflammatory signaling pathways and mediates the release of cytokines and chemokines from tumor cells. These molecules recruit immune cells that subsequently release additional cytokines, pro-angiogenic mediators and growth factors that facilitate tumor growth (12). However, a limited number of studies have addressed the association between HMGB1/TLR4 signaling and the clinicopathological characteristics of OC. Serous cystadenocarcinoma and endometrioid carcinoma are the most common histological types of epithelial OC. In the present study, 20 patients with epithelial OC were examined and the mRNA and protein expressions of HMGB1, TLR4, $\mathrm{NF}-\kappa \mathrm{B}$ and TNF- $\alpha$ in patients with epithelial OC were detected. The aim of the present study was to investigate the expression of HMGB1/TLR4 signaling pathway proteins to further elucidate if they were associated with the clinicopathological 
characteristics of malignant epithelial ovarian cancer (MEOC), and to further elucidate the mechanisms underlying the development and progression of epithelial OC.

\section{Materials and methods}

Ethics statement. The present study was approved by the Institutional Review Board of Yangpu Hospital, Tongji University School of Medicine (Shanghai, China). All biopsy specimens were collected, according to the guidelines of the Declaration of Helsinki. Written informed consent was obtained from all participants.

Participants. From March 2016 to March 2017, 20 patients who underwent comprehensive staging operation or tumor reductive surgery for MEOC at the Gynecological Department of Yangpu Hospital, Tongji University School of Medicine were included in the present study. Patients with MEOC were clinically staged, according to the International Federation of Gynecology and Obstetrics (FIGO) staging system (13), and were diagnosed for the first time during the enrollment period. Tissue samples were collected prior to treatment including surgery, chemotherapy and radiotherapy. Patients who underwent surgery for a benign ovarian condition (BOC; all of them had been identified as serous cystadenoma by histological examination) within the same time period were recruited as the control group. All patients enrolled in the present study had not taken any hormonal therapy in the last three months, including oral contraceptive pills, progestins, gonadotropin-releasing hormone agonists or levonorgestrel intrauterine system. Individuals with other malignant tumors, cardiovascular, autoimmune, endocrine, metabolic, pelvic inflammatory or infectious disease were excluded.

Tissue collection. Tissue samples were collected from patients who underwent surgery for ovarian tumors at the Gynecological Department of Yangpu Hospital (Shanghai, China). MEOC tissue samples were collected from areas that had been macroscopically identified as cancer by pathologists, and the final diagnosis predominantly depended on histological examination of the biopsy. Under strict asepsis, fresh MEOC and $\mathrm{BOC}$ tissue specimens were frozen in liquid nitrogen and stored at $-80^{\circ} \mathrm{C}$ for RNA and protein extraction.

$R N A$ extraction and reverse transcription-quantitative polymerase chain reaction ( $R T-q P C R)$. Total RNA was extracted from the frozen tissue samples using TRIzol $^{\circledR}$ reagent (Invitrogen; Thermo Fisher Scientific, Inc., Waltham, MA, USA). Complementary DNA was synthesized with RevertAid First Strand cDNA Synthesis kit (Fermentas; Thermo Fisher Scientific, Inc.) at $42^{\circ} \mathrm{C}$ for $1 \mathrm{~h}$ and $75^{\circ} \mathrm{C}$ for $5 \mathrm{~min}$. Primer sequences specific for HMGB1, TLR4, nuclear factor (NF)- $\mathrm{kB}$ and tumor necrosis factor (TNF)- $\alpha$ are presented in Table I. qPCR was performed using SYBR Green Master mix on an ABI7300 platform (Thermo Fisher Scientific, Inc.). $\beta$-actin was used as an internal control. The PCR thermocycling conditions were as follows: $94^{\circ} \mathrm{C}$ for $7 \mathrm{~min}$, followed by 40 cycles of $15 \mathrm{sec}$ at $94^{\circ} \mathrm{C}$ and $45 \mathrm{sec}$ at $60^{\circ} \mathrm{C} . \Delta \mathrm{Cq}$ was defined as the difference in the cycle threshold between the target gene and internal control, and $\Delta \Delta \mathrm{Cq}$ was defined as the difference between the
$\Delta \mathrm{Cq}$ values of the test sample and control. The relative expression of the target genes was calculated as $2^{-\Delta \Delta C q}(14)$.

Western blot analysis. Protein was extracted with efficient radioimmunoprecipitation assay histological/cell lysis fluid (Beijing Solarbio Science \& Technology Co., Ltd., Beijing, China), and centrifuged at $12,000 \mathrm{x}$ g for $15 \mathrm{~min}$ at $4^{\circ} \mathrm{C}$. Protein concentration was determined with a bicinchoninic acid protein assay (Thermo Fisher Scientific, Inc., Waltham, MA, USA) and stored at $-80^{\circ} \mathrm{C}$. Total lysates, $15 \mu \mathrm{l}$ per lane were resolved by 10 or $12 \%$ SDS-PAGE, according to the protein molecular weight. Proteins were blotted onto a nitrocellulose membrane and blocked at room temperature for $1 \mathrm{~h}$ with 5\% skim milk powder, and incubated at $4^{\circ} \mathrm{C}$ overnight with the following primary antibodies: HMGB1 (1:300; cat. no. ab77302), TLR4 (1:500; cat. no. ab22048; both Abcam, Cambridge, MA, USA), NF-кB p65 (1:1,000, cat. no. 6956s; Cell Signaling Technology, Inc., Danvers, MA, USA), TNF- $\alpha$ (1:2,000; cat. no. ab9739; Abcam), GAPDH (1:2,000, cat. no. 5174; Cell Signaling Technology,Inc.), diluted in Tris-buffered saline (TBS) containing 1\% skimmed milk. The blots were subsequently washed with TBS, incubated with horseradish peroxidase (HRP)-labeled goat anti-rabbit IgG (1:1,000; cat. no. a0208) HRP-labeled donkey anti-goat IgG (1:1,000; cat. no. a0181) and HRP-labeled goat anti-mouse IgG (1:1,000; cat. no. a0216) secondary antibodies (Beyotime Institute of Biotechnology, Haimen, China) at room temperature for $1 \mathrm{~h}$. Proteins were visualized using an enhanced chemiluminescence western blotting system (Bio-Rad Laboratories, Inc., Hercules, CA, USA). Densitometry was performed using ImageJ bundled with 64-bit Java 1.8.0_112 (National Institutes of Health, Bethesda, MD, USA) to quantify protein expression. GAPDH served as an internal control.

Statistical analysis. All statistical analyses were performed using SPSS software 16.0 (SPSS, Inc., Chicago, IL, USA). $\mathrm{P}<0.05$ was considered to indicate a statistically significant difference. Diagrams were drawn with GraphPad Prism 5 (GraphPad Software, Inc., La Jolla, CA, USA). Data normality was determined with the kurtosis and skewness measures, as well as the Shapiro-Wilk test. Normally distributed data were presented as the mean \pm standard deviation, and intra-group differences were investigated using the Student's t-test. Non-normally distributed data were presented as the median (quartiles), and intra-group differences were determined using the Mann-Whitney U test. Categorical variables were expressed as the number of cases and percentages (\%). Differences between categorical data were evaluated using the $\chi^{2}$ test or Fisher's exact test. A Pearson's correlation test was conducted to investigate the association between the expression levels of HMGB1, TLR4, NF-кB and TNF- $\alpha$.

\section{Results}

General patient data. The sociodemographic and clinical characteristics of the groups are presented in Table II. There were no statistically significant differences in age, BMI, fertility or history of prior surgery between the groups $(\mathrm{P}>0.05)$.

Clinicopathological characteristics of patients with MEOC. The 20 patients with MEOC were pathologically diagnosed, 
Table I. Primers used in reverse transcription-quantitative polymerase chain reaction.

\begin{tabular}{|c|c|c|c|}
\hline Gene & Primer sequences $\left(5^{\prime}-3^{\prime}\right)$ & Annealing temperature $\left({ }^{\circ} \mathrm{C}\right)$ & Product size (bp) \\
\hline \multicolumn{4}{|c|}{ HMGB1 } \\
\hline $\mathrm{F}$ & GTGGCTCACGCCTGTAATCC & 61 & 230 \\
\hline $\mathrm{R}$ & GGCACAATCTCGGCTCACTG & & \\
\hline \multicolumn{4}{|l|}{ TLR4 } \\
\hline $\mathrm{F}$ & CCGCTTTCACTTCСТCTCAC & 58 & 182 \\
\hline $\mathrm{R}$ & CATCCTGGCATCATCCTCAC & & \\
\hline \multicolumn{4}{|c|}{ NF-кB } \\
\hline $\mathrm{F}$ & GAATGGCTCGTCTGTAGTG & 56 & 232 \\
\hline $\mathrm{R}$ & TGGTATCTGTGCTCCTCTC & & \\
\hline \multicolumn{4}{|c|}{ TNF- $\alpha$} \\
\hline $\mathrm{F}$ & CCTGGTATGAGCCCATCTATC & 57 & 218 \\
\hline $\mathrm{R}$ & AGGTTGAGGGTGTCTGAAG & & \\
\hline \multicolumn{4}{|c|}{$\beta$-actin } \\
\hline $\mathrm{F}$ & CAAGATCATTGCTCCTCCTG & 56 & 90 \\
\hline $\mathrm{R}$ & ATCCACATCTGCTGGAAGG & & \\
\hline
\end{tabular}

F, forward; R, reverse; HMGB1, high mobility group box chromosomal protein 1; TLR4, toll-like receptor 4; NF- $\mathrm{B}$, nuclear factor of $\kappa \mathrm{B}$; TNF- $\alpha$, tumor necrosis factor- $\alpha$.

Table II. General patient data.

\begin{tabular}{|c|c|c|c|}
\hline Patient characteristics & $\operatorname{MEOC}(n=20)$ & BOC $(n=20)$ & P-value \\
\hline Age, y (range) & $57.85 \pm 9.60(38-76)$ & $53.95 \pm 12.62(22-70)$ & $0.278^{\mathrm{a}}$ \\
\hline $\mathrm{BMI}, \mathrm{kg} / \mathrm{m}^{2}$ (range) & $23.07 \pm 3.04(18.82-28.74)$ & $22.21 \pm 2.87(18.14-27.24)$ & $0.363^{\mathrm{a}}$ \\
\hline Median parity (lower quartile, upper quartile) & $1(1,1)$ & $1(1,1.75)$ & $0.768^{\mathrm{b}}$ \\
\hline Median abortion (lower quartile, upper quartile) & $1.5(1,2)$ & $1(1,2)$ & $0.489^{\mathrm{b}}$ \\
\hline Previous abdominal surgery $(\%)$ & & & $1.000^{\mathrm{c}}$ \\
\hline General surgery & $4(20)$ & $4(20)$ & \\
\hline Gynecological surgery & $7(35)$ & $6(30)$ & \\
\hline
\end{tabular}

BMI, body mass index; MEOC, malignant epithelial ovarian cancer; BOC, ovarian cysts. Data are presented as the mean \pm standard deviation. ${ }^{\text {a }}$ Student's t-test, ${ }^{b}$ Mann-Whitney U test, ${ }^{\mathrm{c}} \chi^{2}$ test or Fisher's exact test.

and included $11(55.00 \%)$ cases of serous cystadenocarcinoma and nine $(45.00 \%)$ cases of endometrioid carcinoma. According to the FIGO staging system, there were nine $(45.00 \%)$ cases of early-stage (stage I or II) MEOC and 11 (55.00\%) cases of advanced-stage (stage III or IV) MEOC. In addition, according to the degree of differentiation, the tumors were classified into six $(30.00 \%)$ cases of poorly differentiated MEOC and 14 $(70.00 \%)$ cases of moderately and well-differentiated MEOC.

HMGB1, TLR4, NF- $\kappa B$ and TNF- $\alpha$ mRNA and protein expression is increased in MEOC. RT-qPCR analysis demonstrated that the mRNA expression of HMGB1, TLR4, NF- $\kappa \mathrm{B}$ and TNF- $\alpha$ was significantly increased in the MEOC group, compared with the BOC group $(\mathrm{P}<0.01$; Fig. 1). In addition, western blot analysis was performed to detect the protein expression of HMGB1, TLR4, NF- $\kappa \mathrm{B}$ and TNF- $\alpha$ in the MEOC and BOC groups. As presented in Fig. 2, the protein expression of
HMGB1, TLR4, NF- $\kappa$ B and TNF- $\alpha$ was significantly increased in the MEOC group, compared with the BOC group $(\mathrm{P}<0.01)$.

$H M G B 1, T L R 4, N F-\kappa B$ and TNF- $\alpha$ expression levels are increased in advanced-stage MEOC. In the present study, patients with MEOC were divided into two subgroups according to the tumor stage. The gene expression levels of HMGB1, TLR4, NF- $\kappa \mathrm{B}$ and TNF- $\alpha$ in the advanced-stage group were significantly increased, compared with the early-stage group $(\mathrm{P}<0.01$; Fig. 3A). Similar results were obtained at the protein level, demonstrating that the protein expression of HMGB1, TLR4, NF- $\kappa \mathrm{B}$ and TNF- $\alpha$ in the advanced-stage group was significantly increased, compared with the early-stage group $(\mathrm{P}<0.01$; Fig. 3B).

HMGB1, TLR4, NF- $\kappa B$ and TNF- $\alpha$ expression levels are increased in MEOC with poor differentiation. In addition, 


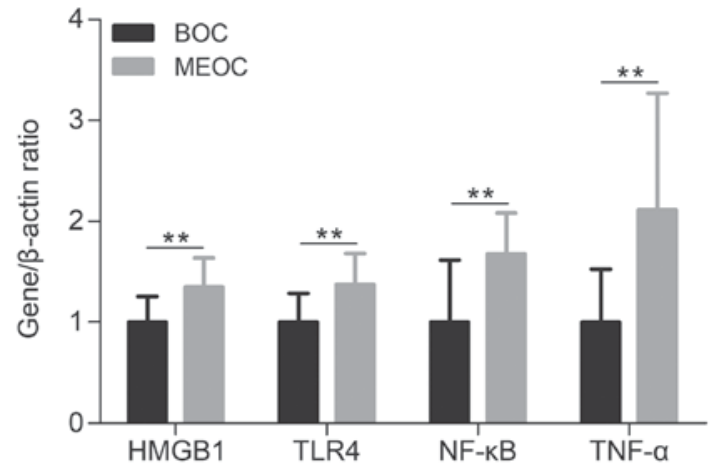

Figure 1. Expression of HMGB1, TLR4, NF- $\mathrm{BB}$ and TNF- $\alpha$ mRNA in the MEOC and BOC groups. ${ }^{* *} \mathrm{P}<0.01$ vs. BOC group. MEOC, malignant epithelial ovarian cancer; BOC, benign ovarian cyst; HMGB1, high mobility group box chromosomal protein 1; TLR4, toll-like receptor 4; NF- $\mathrm{BB}$, nuclear factor of $\kappa B$; TNF- $\alpha$, tumor necrosis factor- $\alpha$.
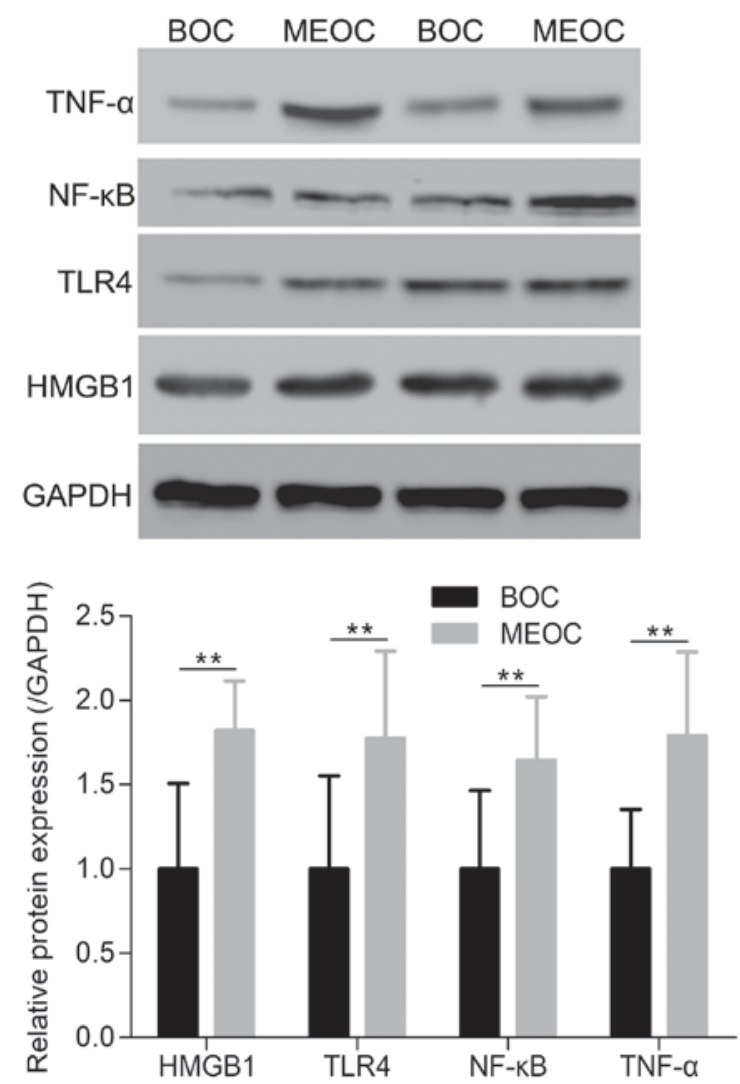

Figure 2. Western blot analysis of HMGB1, TLR4, NF- $\mathrm{KB}$ and TNF- $\alpha$ protein expression in the MEOC and BOC groups. ${ }^{* *} \mathrm{P}<0.01$ vs. BOC group. MEOC, malignant epithelial ovarian cancer; BOC, benign ovarian cyst; HMGB1, high mobility group box chromosomal protein 1; TLR4, toll-like receptor 4; $N F-\kappa B$, nuclear factor of $\kappa B$; TNF- $\alpha$, tumor necrosis factor- $\alpha$.

patients with MEOC were divided into two subgroups according to the degree of differentiation. As presented in Fig. 4, the gene (Fig. 4A) and protein (Fig. 4B) expression of HMGB1, TLR4, NF- $\kappa B$ and TNF- $\alpha$ in the poorly differentiated group was significantly increased, compared with the moderately and well-differentiated group $(\mathrm{P}<0.01)$.

Correlations between the expression levels of HMGB1, TLR4, $N F-\kappa B$ and TNF- $\alpha$ in MEOC group. Data analysis revealed
Table III. Correlation between the mRNA expression levels of HMGB1, TLR4, NF- $\mathrm{kB}$ and TNF- $\alpha$ in malignant epithelial ovarian cancer.

\begin{tabular}{|c|c|c|c|c|}
\hline & HMGB1 & TLR4 & NF-kB & TNF- $\alpha$ \\
\hline HMGB1 & 1 & $0.983^{\mathrm{a}}$ & $0.973^{\mathrm{a}}$ & $0.989^{\mathrm{a}}$ \\
\hline TLR4 & $0.983^{\mathrm{a}}$ & 1 & $0.953^{\mathrm{a}}$ & $0.967^{\mathrm{a}}$ \\
\hline $\mathrm{NF}-\kappa \mathrm{B}$ & $0.973^{\mathrm{a}}$ & $0.953^{\mathrm{a}}$ & 1 & $0.944^{\mathrm{a}}$ \\
\hline TNF- $\alpha$ & $0.989^{\mathrm{a}}$ & $0.967^{\mathrm{a}}$ & $0.944^{\mathrm{a}}$ & 1 \\
\hline
\end{tabular}

${ }^{\mathrm{a}} \mathrm{P}<0.01$. HMGB1, high mobility group box chromosomal protein 1 ; TLR4, toll-like receptor 4 ; NF- $\kappa B$, nuclear factor of $\kappa B$; TNF- $\alpha$, tumor necrosis factor- $\alpha$.

Table IV. Correlation between the protein expression levels of HMGB1, TLR4, NF-kB and TNF- $\alpha$ in malignant epithelial ovarian cancer.

\begin{tabular}{|c|c|c|c|c|}
\hline & HMGB1 & TLR4 & NF- $\kappa B$ & TNF- $\alpha$ \\
\hline HMGB1 & 1 & $0.968^{\mathrm{a}}$ & $0.970^{\mathrm{a}}$ & $0.971^{\mathrm{a}}$ \\
\hline TLR4 & $0.968^{\mathrm{a}}$ & 1 & $0.935^{\mathrm{a}}$ & $0.971^{\mathrm{a}}$ \\
\hline NF-кB & $0.970^{\mathrm{a}}$ & $0.935^{\mathrm{a}}$ & 1 & $0.950^{\mathrm{a}}$ \\
\hline TNF- $\alpha$ & $0.971^{\mathrm{a}}$ & $0.971^{\mathrm{a}}$ & $0.950^{\mathrm{a}}$ & 1 \\
\hline
\end{tabular}

${ }^{\mathrm{a}} \mathrm{P}<0.01$. HMGB1, high mobility group box chromosomal protein 1 ; TLR4, toll-like receptor 4 ; NF- $\kappa \mathrm{B}$, nuclear factor of $\kappa \mathrm{B}$; TNF- $\alpha$, tumor necrosis factor- $\alpha$.

that there was a significant positive correlation between the mRNA and protein expression levels of HMGB1, TLR4, $N F-\kappa B$ and TNF- $\alpha$ in MEOC $(\mathrm{P}<0.01)$. The values of $r$ are presented in Tables III and IV.

\section{Discussion}

Ovarian cancer is the leading cause of cancer-associated mortality in gynecology worldwide. MEOC is successfully treated in $<40 \%$ of women, due to the lack of effective screening strategies and the non-specific nature of early signs and symptoms associated with this disease, resulting in an advanced stage diagnosis for the majority of patients $(15,16)$. Tumor recurrence and metastasis are considered the major reasons for poor clinical outcomes and mortality. Therefore, clarification of the mechanism underlying the invasion and metastasis of MEOC will provide further insight into the development and progression of OC (10). Inflammation is an essential element in tumorigenesis. HMGB1 is a key DAMP. DAMPs are molecules released from necrotic cells as intrinsic danger signals, which induce inflammation and trigger innate immunity (17). TLRs trigger an inflammatory response and cell survival in the tumor microenvironment, and TLR4 is known to be a receptor of HMGB1 (12). A number of previous studies have confirmed the tumor-facilitating effect of HMGB1. For example, HMGB1 is increased in ovarian, colorectal, lung and gastric 

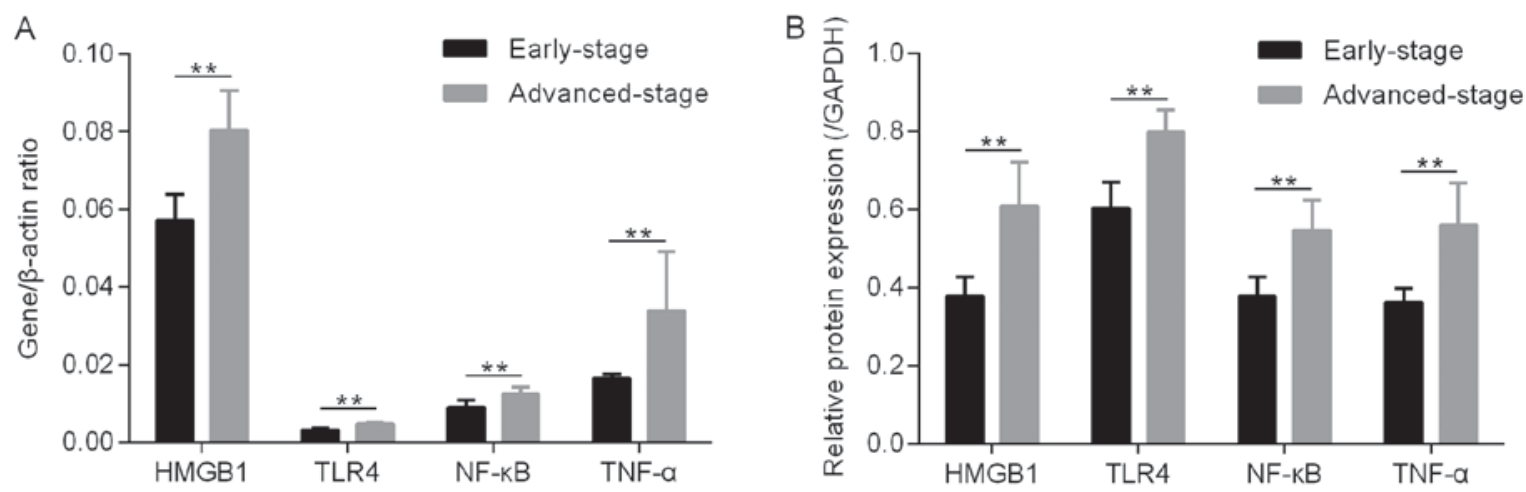

Figure 3. HMGB1, TLR4, NF- $\mathrm{BB}$ and TNF- $\alpha$ expression levels in the advanced and early stages of MEOC. Expression was significantly increased at the (A) gene and (B) protein expression level in advanced-stage MEOC, compared with the early-stage. ${ }^{* *} \mathrm{P}<0.01$ vs. early-stage. MEOC, malignant epithelial ovarian cancer; HMGB1, high mobility group box chromosomal protein 1; TLR4, toll-like receptor 4; NF- $\mathrm{kB}$, nuclear factor of $\kappa \mathrm{B}$; TNF- $\alpha$, tumor necrosis factor- $\alpha$.
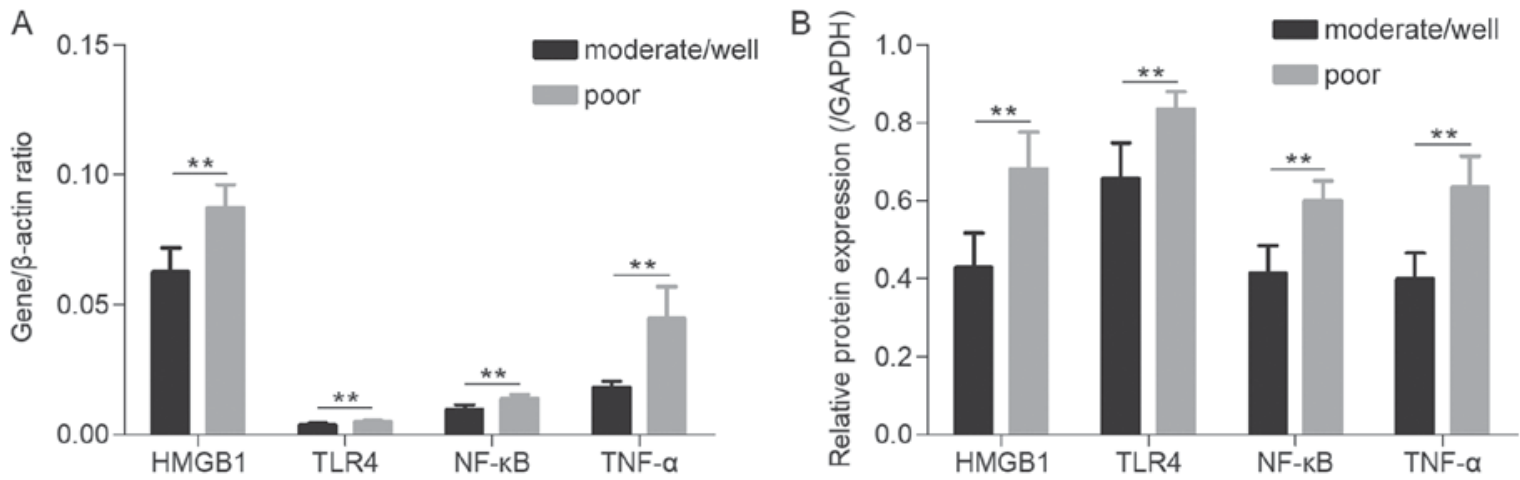

Figure 4. HMGB1, TLR4, NF- $\mathrm{kB}$ and TNF- $\alpha$ expression levels in different degrees of tumor cell differentiation. Expression was significantly increased at the (A) gene and (B) protein expression level in poorly differentiated malignant epithelial ovarian cancer. ${ }^{* *} \mathrm{P}<0.01$ vs. the moderately/well-differentiated group. HMGB1, high mobility group box chromosomal protein 1 ; TLR4, toll-like receptor 4; NF- $\kappa B$, nuclear factor of $\kappa B$; TNF- $\alpha$, tumor necrosis factor- $\alpha$.

cancer, indicating that HMGB1 is an important mediator for cancer transformation, proliferation and invasion $(7,8,10)$. Furthermore, it has recently been demonstrated that activation of TLR4/NF- $\mathrm{B}$ signaling by DAMPs may contribute to an inflammatory microenvironment that drives a more aggressive phenotype with poorer clinical outcomes in patients with MEOC $(11,18)$.

Wang et al (3) performed a meta-analysis that revealed that HMGB1 levels in the tissue and serum of patients with OC are significantly higher compared with those detected in benign tumor and normal ovarian samples. The effect of HMGB1 on cancer types may be mediated by multiple surface receptors, including TLRs (3). In the present study, the mRNA expression levels of HMGB1, TLR4, NF- $\kappa$ B and TNF- $\alpha$ were determined in 20 patients with MEOC and compared with the expression in 20 patients with BOC. It was demonstrated that the mRNA expression of HMGB1 in MEOC was significantly increased compared with the BOC group. The same result was obtained at the protein expression level, which was consistent with a previous study (3), suggesting that HMGB1 may serve a pivotal role in the development of OC. Furthermore, the expression levels of TLR4, a HMGB1 receptor, in addition to the expression of downstream effectors $\mathrm{NF}-\kappa \mathrm{B}$ and $\mathrm{TNF}-\alpha$, were significantly increased in the MEOC group, compared with in the BOC group. These results indicated that the HMGB1/TLR4 signaling pathway may be implicated in the development of the tumor-associated inflammatory microenvironment, which subsequently may serve a pivotal role in MEOC carcinogenesis and clinical outcomes.

HMGB1 has recently been identified to be overexpressed in malignant $\mathrm{OC}$, and associated with poor clinicopathological features and prognosis (8). Chen et al (10) reported that knockdown of HMGB1 suppresses OC cell proliferation and inhibits cell migration and invasion, which is accompanied by decreased cyclin D1, proliferating cell nuclear antigen, matrix metalloproteinase (MMP)2 and MMP9 mRNA expression and enzymatic activity. In order to elucidate whether the HMGB1/TLR4 signaling pathway was associated with the clinicopathological characteristics of MEOC, the expression levels of HMGB1, TLR4, $\mathrm{NF}-\kappa \mathrm{B}$ and TNF- $\alpha$ at different tumor stages and differentiation grades were evaluated. The results revealed that the gene and protein expression levels of HMGB1, TLR4, NF- $\kappa$ B and TNF- $\alpha$ in the advanced-stage and poorly differentiated groups were significantly higher compared with those in the early-stage and well/moderately differentiated group, respectively, indicating that the HMGB1/TLR4 signaling pathway was associated with the tumor stage and degree of tumor cell differentiation in MEOC. In addition, the correlation between the expression of HMGB1, TLR4, NF- $\kappa$ B and TNF- $\alpha$ in MEOC group was evaluated and 
it was demonstrated that all the parameters were positively correlated with each other. It is known that the HMGB1/TLR4 signaling pathway regulates cell proliferation and survival, and creates a tumor microenvironment that facilitates tumor growth by inducing immune cell expansion and integrating inflammatory responses (19). Considering these previous findings and those obtained from the present study, it was therefore concluded that increased HMGB1/TLR4 in the inflammatory immune signaling system may be involved in MEOC tumor stage and differentiation. Furthermore, this may have been mediated via the downstream $\mathrm{NF}-\kappa \mathrm{B}$ signaling pathway.

However, there are certain limitations in the present study. First, as a result of the ethical and experimental limitations, only 20 patients with BOC were recruited as the control group, with no comparison to normal ovarian tissue. Secondly, patient data during hospitalization only were obtained for analysis, which did not contain information concerning postoperative recurrence and disease-free survival. In addition, cytology associated experiments were not conducted in the present study. Therefore, further studies with larger sample sizes are required to avoid these limitations and verify the findings of the present study.

In conclusion, it was demonstrated that components involved in the HMGB1/TLR4 signaling pathway and its downstream effectors were overexpressed and associated with MEOC tumor stage and differentiation. This may have be mediated via the NF- $\kappa \mathrm{B}$ signaling pathway. These findings further elucidated the mechanisms underlying the development and progression of MEOC.

\section{Acknowledgements}

Not applicable.

\section{Funding}

The present study was supported by the Fundamental Research Funds for the Central Universities (grant no. 1516219014).

\section{Availability of data and materials}

The datasets used and/or analyzed during the current study are available from the corresponding author on reasonable request.

\section{Authors' contributions}

$\mathrm{HK}, \mathrm{RC}$ and WG conceived and designed the experiments. CJ performed the experiments, created the figures and wrote the manuscript. XQ and WY contributed to statistical analysis and revision of the manuscript. HK participated in sample collection. ZC made substantial contributions to the conception and design of the study, revised the manuscript critically for important intellectual content and gave final approval of the version to be published. All authors reviewed the manuscript and contributed to patient management. All authors read and approved the final version of the manuscript.

\section{Ethics approval and consent to participate}

The present study was approved by the Institutional Review Board of Yangpu Hospital, Tongji University School of
Medicine. All biopsy specimens were collected, according to the guidelines of the Declaration of Helsinki. Written informed consent was obtained from all participants.

\section{Patient consent for publication}

Written informed consent was obtained from all participants.

\section{Competing interests}

The authors declare that they have no competing interests.

\section{References}

1. Jayson GC, Kohn EC, Kitchener HC and Ledermann JA: Ovarian cancer. Lancet 384: 1376-1388, 2014.

2. Luo N, Guo J, Chen L, Yang W, Qu X and Cheng Z: ARHGAP10, downregulated in ovarian cancer, suppresses tumorigenicity of ovarian cancer cells. Cell Death Dis 7: e2157, 2016.

3. Wang H, Li Z, Sun Y, Xu Z, Han J, Song B, Song W, Qin C and Yin L: Relationship between high-mobility group box 1 overexpression in ovarian cancer tissue and serum: A meta-analysis. Onco Targets Ther 8: 3523-3531, 2015.

4. Li Y, Tian J, Fu X, Chen Y, Zhang W, Yao H and Hao Q: Serum high mobility group box protein 1 as a clinical marker for ovarian cancer. Neoplasma 61: 579-584, 2014.

5. Zhou LY, Shi LY and Xiao Y: Changes of HMGB1 expression on angiogenesis of ovarian cancer and its mechanism. J Biol Regul Homeost Agents 30: 233-238, 2016.

6. Zhang W, Tian J and Hao Q: HMGB1 combining with tumor-associated macrophages enhanced lymphangiogenesis in human epithelial ovarian cancer. Tumour Biol 35: 2175-2186, 2014.

7. Paek J, Lee M, Nam EJ, Kim SW and Kim YT: Clinical impact of high mobility group box 1 protein in epithelial ovarian cancer. Arch Gynecol Obstet 293: 645-650, 2016.

8. Li S and Wei Y: Association of HMGB1, BRCA1 and P62 expression in ovarian cancer and chemotherapy sensitivity. Oncol Lett 15: 9572-9576, 2018.

9. Ju LL, Zhao CY, Ye KF, Yang H and Zhang J: Expression and clinical implication of Beclin1, HMGB1, p62, survivin, BRCA1 and ERCC1 in epithelial ovarian tumor tissues. Eur Rev Med Pharmacol Sci 20: 1993-2003, 2016.

10. Chen J, Liu X, Zhang J and Zhao Y: Targeting HMGB1 inhibits ovarian cancer growth and metastasis by lentivirus-mediated RNA interference. J Cell Physiol 230: 2579, 2015.

11. Li Z, Block MS, Vierkant RA, Fogarty ZC, Winham SJ, Visscher DW, Kalli KR, Wang C and Goode EL: The inflammatory microenvironment in epithelial ovarian cancer: A role for TLR4 and MyD88 and related proteins. Tumor Biol 37: 13279-13286, 2016.

12. Husseinzadeh $\mathrm{N}$ and Davenport SM: Role of toll-like receptors in cervical, endometrial and ovarian cancers: A review. Gynecol Oncol 135: 359-363, 2014.

13. Prat J; FIGO Committee on Gynecologic Oncology: Staging classification for cancer of the ovary, fallopian tube, and peritoneum. Int J Gynaecol Obstet 124: 1-5, 2014.

14. Livak KJ and Schmittgen TD: Analysis of relative gene expression data using real-time quantitative PCR and the 2(-Delta Delta C(T)) method. Methods 25: 402-408, 2001.

15. Cheng Z, Guo J, Chen L, Luo N, Yang W and Qu X: Overexpression of TMEM158 contributes to ovarian carcinogenesis. J Exp Clin Cancer Res 34: 75, 2015.

16. Kobayashi M, Sawada K and Kimura T: Potential of integrin inhibitors for treating ovarian cancer: A literature review. Cancers (Basel) 9: pii: E83, 2017.

17. Waki K, Kawano K, Tsuda N, Ushijima K, Itoh K and Yamada A: Plasma levels of high-mobility group box 1 during peptide vaccination in patients with recurrent ovarian cancer. J Immunol Res 2017: 1423683, 2017.

18. Sun NK, Huang SL, Chang TC and Chao CC: TLR4 and NFאB signaling is critical for taxol resistance in ovarian carcinoma cells. J Cell Physiol 233: 2489-2501, 2018.

19. Jiang C, Liu C, Guo J, Chen L, Luo N, Qu X, Yang W, Ren Q and Cheng Z: The expression of Toll-like receptors in eutopic and ectopic endometrium and its implication in the inflammatory pathogenesis of adenomyosis. Sci Rep 7: 7365, 2017. 